\title{
Mammary-specific deletion of parathyroid hormone-related protein preserves bone mass during lactation
}

\author{
Joshua N. VanHouten, ${ }^{1}$ Pamela Dann, ${ }^{1}$ Andrew F. Stewart, ${ }^{2}$ Christine J. Watson, ${ }^{3}$ \\ Michael Pollak, ${ }^{4}$ Andrew C. Karaplis, ${ }^{5}$ and John J. Wysolmerski ${ }^{1}$ \\ ${ }^{1}$ Section of Endocrinology and Metabolism, Department of Internal Medicine, Yale University School of Medicine, \\ New Haven, Connecticut, USA \\ ${ }^{2}$ Division of Endocrinology, University of Pittsburgh School of Medicine, Pittsburgh, Pennsylvania, USA \\ ${ }^{3}$ Department of Pathology, University of Cambridge, Cambridge, United Kingdom \\ ${ }^{4}$ Department of Oncology and Department of Medicine, and \\ ${ }^{5}$ Division of Endocrinology, Department of Medicine, McGill University, Montreal, Quebec, Canada
}

\begin{abstract}
Large amounts of calcium are transferred to offspring by milk. This demand results in negative calcium balance in lactating mothers and is associated with rapid bone loss. The mechanisms of bone loss during lactation are only partly understood. Several studies have suggested that parathyroid hormone-related protein (PTHrP) might be secreted into the circulation by the lactating mammary gland and regulate bone turnover during lactation. Because mammary development fails in the absence of PTHrP, conventional PTHrP knockout mice cannot be used to address this possibility. To examine this hypothesis, we therefore used mice carrying a $\beta$-lactoglobulin promoter-driven Cre transgene, one null PTHrP allele, and one floxed PTHrP allele. Expression of Cre specifically in mammary epithelial cells during late pregnancy and lactation resulted in efficient deletion of the PTHrP gene; mammary gland PTHrP mRNA and milk PTHrP protein were almost completely absent. Removal of PTHrP from the lactating mammary glands resulted in reductions in levels of circulating PTHrP and 1,25-dihydroxy vitamin D and urinary cAMP. In addition, bone turnover was reduced and bone loss during lactation was attenuated. We conclude that during lactation mammary epithelial cells are a source of circulating PTHrP that promotes bone loss by increasing rates of bone resorption.
\end{abstract}

J. Clin. Invest. 112:1429-1436 (2003). doi:10.1172/JCI200319504.

\section{Introduction}

Parathyroid hormone-related protein (PTHrP) was first identified as the circulating factor causing a common paraneoplastic syndrome known as humoral hypercalcemia of malignancy (HHM) (1). PTHrP is evolutionarily related to parathyroid hormone (PTH), and the two proteins share sequence and structural homology in their amino termini that allow both to bind and to activate the same type I PTH/PTHrP receptor (PTH1R). Unlike PTH, PTHrP is widely expressed and does not

Received for publication July 16, 2003, and accepted in revised form August 26, 2003.

Address correspondence to: John J. Wysolmerski, Anlyan Center for Medical Research and Education, Room S131, 333 Cedar Street, New Haven, Connecticut 06520-8020, USA.

Phone: (203) 785-7447; Fax: (203) 785-6015;

E-mail: john.wysolmerski@yale.edu.

Conflict of interest: The authors have declared that no conflict of interest exists.

Nonstandard abbreviations used: parathyroid hormone-related protein (PTHrP); humoral hypercalcemia of malignancy (HHM); parathyroid hormone (PTH); type I PTH/PTHrP receptor (PTH1R); $\beta$-lactoglobulin (BLG); immunoradiometric assay (IRMA); C-telopeptides of type I collagen (CTx); peripheral quantitative computerized tomography ( $\mathrm{PQCT}$ ); mammary epithelial cell (MEC); osteoclast surface per bone surface (OcS/BS); number of osteoclasts per bone perimeter (NOc/BPm); number of osteoblasts $(\mathrm{ObN})$; osteoblast surface $(\mathrm{ObS})$; bone formation rate (BFR); tissue volume (TV); bone volume (BV); trabecular number $(\mathrm{TbN})$; trabecular separation (TbSp); bone mineral density (BMD) normally act as an endocrine regulator of calcium homeostasis. Rather, it has been shown to mediate autocrine, paracrine, and intracrine interactions regulating cellular growth and physiology in a variety of tissues (2-4).

One of the first physiological sites found to produce PTHrP was the mammary gland (5). It was initially shown that PTHrP mRNA was expressed in the lactating breast and that copious amounts of PTHrP were secreted into milk $(6,7)$, where its concentration is 1,000 times that in plasma from patients with HHM (7). Subsequent studies have demonstrated that PTHrP has important developmental functions in the breast. Disruption of either PTHrP or the PTH1R in mice and in humans results in the failure of embryonic mammary development and a complete lack of breast epithelium $(8,9)$. PTHrP also appears to regulate ductal branching morphogenesis during puberty $(10,11)$. PTHrP's function during lactation has remained uncertain, however. Some studies have suggested that PTHrP might be involved in regulating calcium transport into milk (12-15). Others have suggested that PTHrP might regulate mammary blood flow during lactation (16). PTHrP in milk might also have effects on the neonatal gut or enter the neonatal circulation and exert systemic effects (17-19). Finally, it has been suggested that PTHrP, made by the lactating breast, enters the maternal circulation and acts as an endocrine mediator of accelerated bone loss.

Lactation is associated with a rapid, but reversible, reduction in bone mass due to accelerated bone resorp- 
tion $(20,21)$. It has been demonstrated that bone loss during lactation is not dependent on either of the classical calciotropic hormones, vitamin $\mathrm{D}$ and $\mathrm{PTH}$ (20-22). Thus, the regulation of bone loss in this setting has remained enigmatic. Several lines of evidence have suggested that PTHrP might be a mediator of increased bone resorption (23-28), yet not all data support this hypothesis $(29,30)$. Therefore, the evidence suggesting an endocrine role for PTHrP during lactation remains inconclusive.

We wished to study the biological function of PTHrP in the mammary gland during lactation by ablating its gene. Deletion of the PTHrP gene using standard genetargeting techniques results in neonatal lethality due to skeletal dysplasia (31). These mice also fail to form mammary glands (9). We therefore required a targeting strategy that would disrupt the gene only in the mammary gland, after it was fully formed. We took advantage of the ovine $\beta$-lactoglobulin (BLG) promoter to direct expression of the bacterial recombinase, Cre, to mammary epithelial cells during late pregnancy and lactation (32). By breeding these mice to mice carrying a floxed PTHrP gene (33), we successfully removed PTHrP from the lactating mammary gland without affecting mammary development. Our data show that the mammary gland secretes PTHrP into the circulation during lactation and that mammary-derived PTHrP is a mediator of bone loss during lactation.

\section{Methods}

Breeding BLG-Cre/PTHrPlox/- mice. BLG-Cre mice were mated with $\mathrm{PTHrP}^{+/-}$mice, and offspring carrying both the BLG-Cre transgene and the PTHrP null allele were identified by PCR of genomic tail DNA as described previously $(9,32)$. These mice were then mated with mice homozygous for the floxed PTHrP allele $\left(P T H r P^{l o x} / l o x\right)$, in which the main coding exon of the mouse PTHrP gene is flanked by loxP sites (33). This breeding produced both the control littermate PTHrPlox/- mice and the mammary-targeted BLGCre/PTHrPlox/- mice. At 8 weeks of age, female PTHrPlox/- mice and BLG-Cre/PTHrPlox/- mice were mated with CD1 males (Charles River Laboratories, Wilmington, Massachusetts, USA). After the mice became pregnant for the third time, males were removed. All analyses were done on day 12 of the third lactation, unless otherwise stated. Mice had access to rodent chow RMH-3000 (Purina Mills Inc., Indianapolis, Indiana, USA) containing $1 \%$ calcium at all times.

Analysis of mammary PTHrP expression in BLG-Cre/ PTHrPlox/- mice. RNA was isolated from mammary

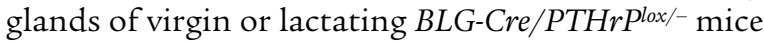
and control PTHrPlox/- littermates using TRIzol (Invitrogen Corp., Carlsbad, California, USA). Ribonuclease protection analysis was performed on $40 \mu \mathrm{g}$ of total RNA as described previously $(9,34)$. PTHrP protein expression was analyzed in milk using a two-site immunoradiometric assay (IRMA) specific for PTHrP(1-86) (sensitivity, 0.2 pM; Diagnostic Systems
Laboratories Inc., Webster, Texas, USA). Milk was collected after an intraperitoneal injection of 0.1 milliInternational units of oxytocin (Sigma-Aldrich, St. Louis, Missouri, USA) and was diluted in mouse plasma (Hilltop Lab Animals, Scottsdale, Pennsylvania, USA) prior to being assayed.

Biochemical measurements in lactating BLG-Cre/PTHrPlox/mice. On day 12 of lactation, blood was collected by cardiac puncture into syringes containing $28 \mathrm{U}$ heparin (Becton Dickinson and Co., Franklin Lakes, New Jersey, USA) and added to tubes containing a protease inhibitor cocktail (Roche Molecular Biochemicals, Indianapolis, Indiana, USA) (final concentrations, 200 $\mu \mathrm{g} / \mathrm{ml}$ aprotinin, $30 \mu \mathrm{g} / \mathrm{ml}$ leupeptin, $7 \mu \mathrm{g} / \mathrm{ml}$ pepstatin, $6 \mathrm{mM}$ EDTA). Plasma was stored for up to 1 month at $-70^{\circ} \mathrm{C}$, and PTHrP(1-36) was measured using a two-site IRMA with a sensitivity of $0.15 \mathrm{pM}$ (35). As biomarkers of PTH1R activation in vivo, urinary cAMP was measured in duplicate using a double-Ab RIA (sensitivity $0.05 \mathrm{pM}$ ) (36) and plasma 1,25-dihydroxy vitamin D levels were measured with a protein receptorbinding assay (sensitivity, $0.5 \mathrm{pg}$ ) (37). Urine was collected upon sacrifice. Circulating PTH was measured in plasma using an IRMA for rat PTH (sensitivity 0.1 pM; Immutopics International LLC, San Clemente, California, USA). Plasma calcium and milk calcium were measured with an atomic absorptiometer (model 2380; Perkin-Elmer Corp., Norwalk, Connecticut, USA). Milk was diluted 1:100 in distilled water prior to measurement of calcium. Urinary cross-linked C-telopeptides of type I collagen (CTx) were measured in duplicate with the RatLaps enzyme immunoassay (Nordic Bioscience Diagnostics, Atlanta, Georgia, USA) and corrected for creatinine concentrations, as determined by the picric acid method (Sigma-Aldrich). Osteocalcin concentrations were measured in duplicate plasma samples with an RIA (sensitivity, $2.2 \mathrm{ng} / \mathrm{ml}$ ) (38).

Histomorphometry and bone density in lactating BLGCre/PTHrPlox/- mice. Static and dynamic histomorphometric analysis of tibias was performed by the Yale Core Center for Musculoskeletal Disorders (New Haven, Connecticut, USA) using the Osteomeasure system (OsteoMetrics, Atlanta, Georgia, USA). For dynamic histomorphometry, bones were labeled by injecting mice intraperitoneally with $1 \mathrm{mg}$ mouse calcein (Macalister Bicknell, New Haven, Connecticut, USA) 1 day and 4 days before sacrifice. Densitometry was performed in duplicate at $100-\mu \mathrm{m}$ resolution using Stratec peripheral quantitative computerized tomography (pQCT) (XCT Research SA+, version 5.4B; Norland Medical Systems Inc., White Plains, New York, USA). Additionally, serial BMD measurements were performed on five PTHrPlox/- controls and six BLG-Cre/PTHrPlox/- mice by dual energy $x$-ray absorptiometry (DEXA) using a Lunar PIXImus scanner (LUNAR Corp., Madison, Wisconsin, USA) on day 4 and day 11 of lactation.

Statistics. The differences of the mean values between BLG-Cre/PTHrPlox/- and PTHrPlox/- groups were compared using an unpaired $t$ test. All $t$ tests were two- 

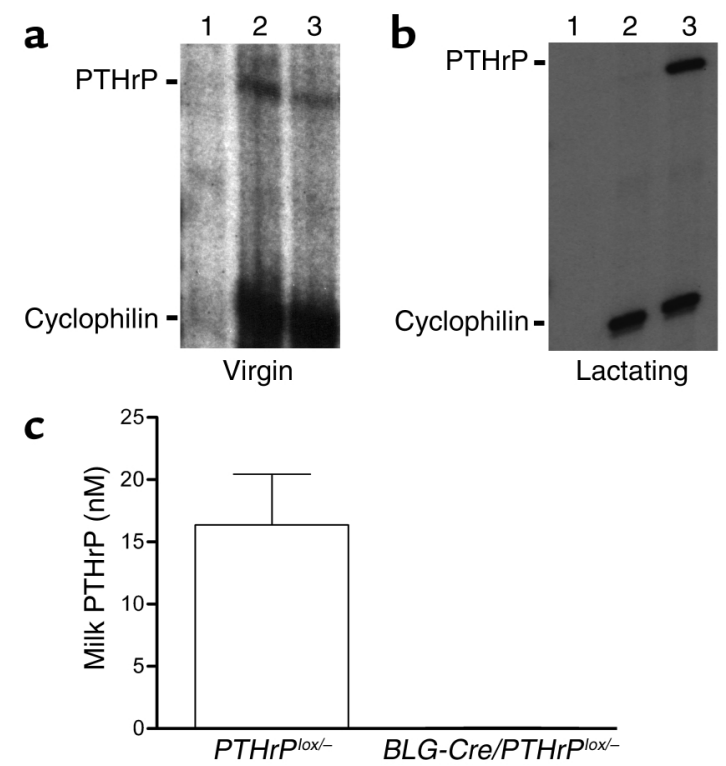

tailed except for the analysis of plasma PTHrP values, where a one-tailed test was used because of the predicted likelihood that PTHrP levels would be lower in the BLG-Cre/PTHrPlox/- mice. A Pearson correlation was used to analyze the relationship between circulating PTHrP and PQCT or urine cAMP. All statistical analyses were carried out using Graph Pad Prism 4.00 for Windows (GraphPad Software for Science Inc., San Diego, California, USA).

\section{Results}

Conditional ablation of PTHrP expression in mammary epithelial cells. PTHrP is required for the formation of the embryonic mammary gland (9), and it regulates ductal development during puberty $(10,11)$. The lactating mammary gland also expresses the PTHrP gene at high levels. To study the role of PTHrP in lactation, we devised a strategy to remove PTHrP from the mammary gland only after development was complete. $B L G$ is an ovine milk protein gene that is expressed in mammary epithelial cells (MECs) beginning only in late pregnancy and during lactation, and the $B L G$ promoter has been successfully used to drive Cre expression in MECs in mice at this time. Therefore, we bred BLG-Cre transgenic mice with PTHrP floxed mice to delete the PTHrP gene (33) in MECs during late pregnancy and lactation. To maximize the efficiency of Cre-mediated deletion of PTHrP, we performed our experiment as follows. First, we used mice that were compound heterozygotes at the

\section{Figure 2}

Mammary gland whole mounts stained with carmine aluminum (a and b) and histological sections stained with hematoxylin and eosin (c and d) from lactating PTHrPlox/- mice (a and c) and BLG-Cre/PTHrPlox/- mice (b and d). The scale bar in b represents $200 \mu \mathrm{m}$, and the scale bar in d represents $5 \mu \mathrm{m}$. BLG-Cre/PTHrPlox/- and control mammary glands appeared to be typical of lactating mammary tissue.

\section{Figure 1}

(a) Ribonuclease protection analysis of PTHrP and cyclophilin transcripts in RNA from yeast (lane 1) and mammary glands from virgin PTHrPlox/- (lane 2) and BLG-Cre/PTHrPlox/- (lane 3) mice shows that PTHrP is normally expressed at low levels; therefore significant recombination has not yet taken place. (b) Ribonuclease protection of PTHrP and cyclophilin in RNA from mammary glands of lactating BLG-Cre/PTHrPlox/- (lane 2) and PTHrPlox/- (lane 3) mice. Yeast RNA (lane 1) was a negative control. The efficiency of BLGCre-mediated recombination is highlighted by the essentially complete lack of PTHrP RNA in the BLG-Cre/PTHrPlox/- mammary glands. (c) PTHrP protein was undetectable (12 of 14) or drastically reduced (2 of 14) in milk from BLG-Cre/PTHrPlox/- mice (mean $0.06 \pm 0.04 \mathrm{nM}, n=14)$ compared with littermate $P T H r P^{l o x} /-$ controls ( $16.4 \pm 4.1 \mathrm{nM}, n=9)$ as a result of the mammary-specific targeting of PTHrP gene deletion.

PTHrP locus, with one null allele and one floxed allele (PTHrPlox/-). Second, experience with conditional gene targeting in the mammary gland has suggested that the proportion of cells undergoing recombination increases with successive reproductive cycles (39). Thus, we analyzed mice on their third lactation. We verified that Cre RNA was expressed in the mammary glands of lactating BLG-Cre/PTHrPlox/- mice by RNase protection analysis (data not shown) and that Cre protein was expressed homogeneously in luminal epithelial cells during lactation using immunohistochemistry (data not shown). Myoepithelial cells did not stain for Cre protein. RNase protection analysis revealed that PTHrP mRNA was expressed at low levels in both the mammary glands from virgin $B L G$-Cre/PTHrPlox/- mice and from control

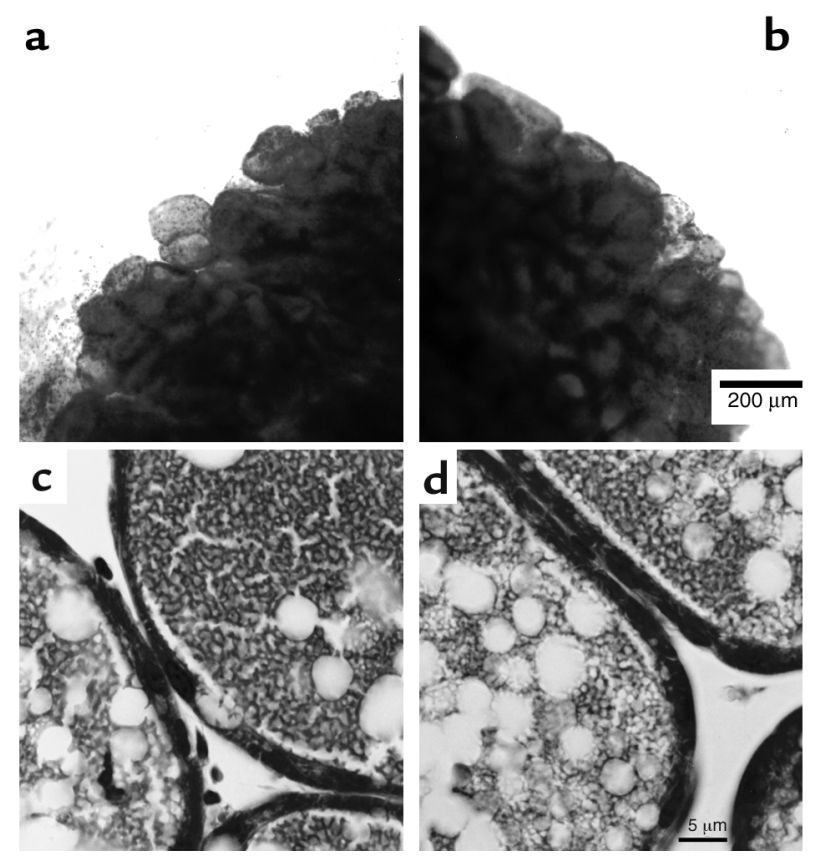


PTHrPlox/- littermates (Figure 1a) before Cre expression was activated. As expected, the mammary glands from PTHrPlox/ controls expressed high levels of PTHrP RNA during lactation. PTHrP mRNA was absent from the $B L G-C r e / P T H r P^{l o x} /-$ glands (Figure 1b), however. To corroborate the successful removal of PTHrP from the BLG-Cre/PTHrPlox/- mammary glands, we also assayed PTHrP levels in milk using a two-site IRMA (Figure 1c). Milk PTHrP levels in controls were $16.4 \pm 4.1 \mathrm{nM}$ (mean $\pm \mathrm{SE}$ ), while milk PTHrP was undetectable in 12 out of 14 BLG-Cre/PTHrPlox/- mice. In the two BLG$\mathrm{Cre} / \mathrm{PTHr}$ lox $^{-}$- milk samples with detectable PTHrP, its concentration was at the assay's limit of sensitivity $(0.2$ $\mathrm{pM})$ before correcting for dilution.

PTHrP is not necessary for lactation. There were no obvious functional defects in lactating BLG-Cre/PTHrPlox/mice. Their litter sizes and the growth rates of their pups were not different from those parameters in $\mathrm{PTHr} \mathrm{Plox} /-_{-}$controls. The average pup weight of BLG$\mathrm{Cre} / \mathrm{PTHrPlox/}$ offspring at postpartum day 12 was $6.50 \pm 0.47 \mathrm{~g}$ compared with $6.55 \pm 0.36 \mathrm{~g}$ for pups nursing $P T H r P^{l o x} /-$ dams. Furthermore, there were no apparent structural defects in the mammary glands of

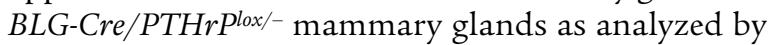
whole mounts (Figure 2, a and b), and the tissue was histologically normal (Figure 2, c and d).

Deletion of PTHrP from the lactating mammary gland decreases circulating PTHrP levels. To determine if the mammary gland is a source of circulating PTHrP during lactation, we measured plasma PTHrP concentrations in the absence of mammary PTHrP expression (Figure 3a). As seen, the level of PTHrP(1-36) in the plasma of lactating $B L G-C r e / P T H r P l o x /-$ mice $(0.73 \pm 0.12$ $\mathrm{pM}$ ) was significantly lower than circulating PTHrP levels in controls $(1.18 \pm 0.19 \mathrm{pM})$, demonstrating that the mammary gland is the source of a significant amount of the PTHrP that circulates during lactation.

Calcium homeostasis in lactating BLG-Cre/PTHrPlox/- mice. Circulating calcium levels (Figure $3 \mathrm{~b}$ ) were not significantly different in BLG-Cre/PTHrPlox/- mice $(8.8 \pm 0.2$ $\mathrm{mg} / \mathrm{dl})$ as compared with $P T H r P^{l o x} /-$ mice $(9.0 \pm 0.3$ $\mathrm{mg} / \mathrm{dl}$ ). Similarly, PTH levels (Figure 3c) were not different in BLG-Cre/PTHrPlox/- as compared with control mice (3.7 \pm 0.9 versus $3.8 \pm 1.5 \mathrm{pM}$, respectively). Despite the lack of change in PTH levels, we did observe reductions in two parameters of PTH1R stimulation in BLG$\mathrm{Cre} / \mathrm{PTHr} \mathrm{Plox}^{\mathrm{lo}}$ mice. Urinary excretion of cAMP was $19.3 \pm 0.8 \mu \mathrm{g} / \mathrm{mmol}$ creatinine in BLG-Cre $/$ PTHrPlox/mice, as compared with $33.9 \pm 0.6 \mu \mathrm{g} / \mathrm{mmol}$ creatinine in controls $(P<0.0001$; Figure $3 \mathrm{~d})$. In addition, urine cAMP levels correlated positively with plasma PTHrP levels $\left(P<0.05 ; r^{2}=0.52\right)$. Levels of plasma 1,25 -dihydroxy vitamin D (Figure 3e) were also significantly lower $(P<0.05)$ in BLG-Cre/PTHrPlox/- animals $(43.5 \pm 2.2$ $\mathrm{pg} / \mathrm{ml})$ compared with controls $(55.9 \pm 5.9 \mathrm{pg} / \mathrm{ml})$. Finally, although the mean concentration of calcium in milk (Figure 3f) was slightly lower in $\mathrm{BLG}$-Cre/PTHr $\mathrm{Plox}^{\mathrm{lo}}$ - mice than it was in controls $(406.7 \pm 39.4$ versus $471.0 \pm 78.5$ $\mathrm{mg} / \mathrm{dl}$ ), this trend was not statistically significant.
Bone turnover in lactating BLG-Cre/PTHrPlox/- mice. To determine if the removal of PTHrP from the mammary glands of BLG-Cre/PTHrPlox/- mice was associated with alterations in bone turnover during lactation, we measured biochemical markers of bone resorption and formation (Figure 4) and performed static and dynamic histomorphometry (Table 1). Urinary CTx levels (Figure 4a) were significantly lower in $B L G-\mathrm{Cre} / \mathrm{PTHrPlox} /-$ mice as compared with controls $(3.98 \pm 0.82$ versus $6.83 \pm 0.29$ $\mu \mathrm{g} / \mathrm{mmol}$ creatinine; $P<0.05)$. Histomorphometric measurements of bone resorption such as the osteoclast surface per bone surface (OcS/BS) and the number of osteoclasts per bone perimeter $(\mathrm{NOc} / \mathrm{BPm})$ were also
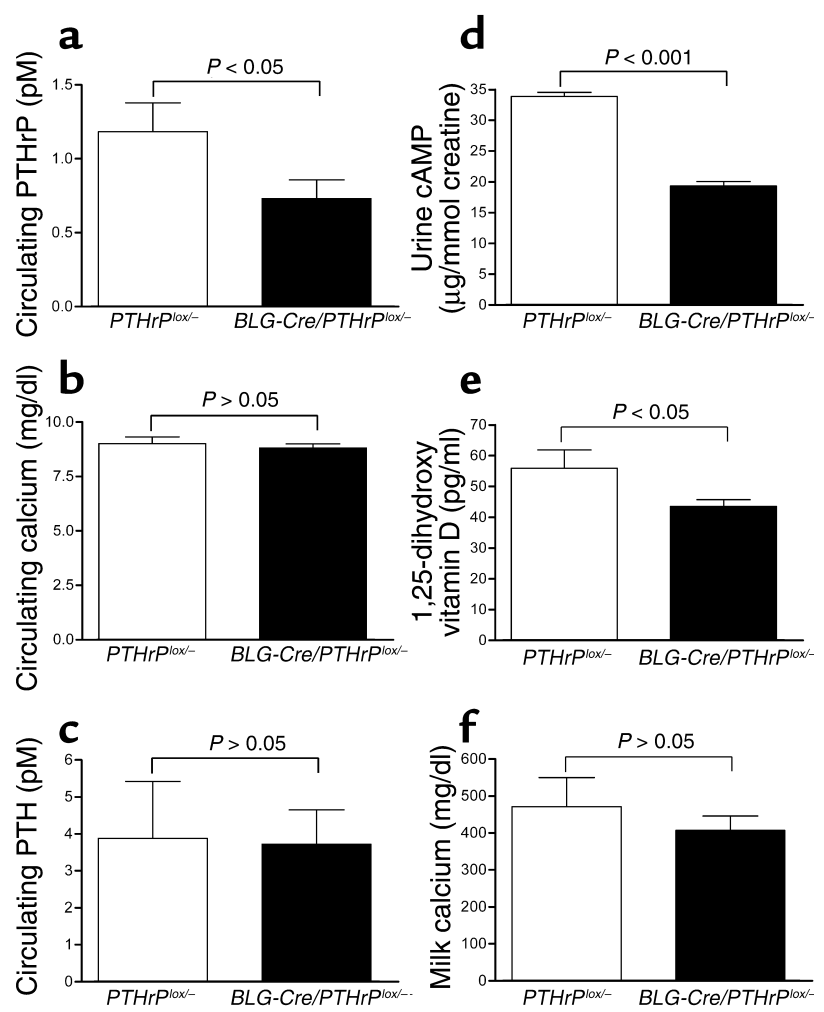

Figure 3

Calcium metabolism in BLG-Cre/PTHrPlox/- mice. Circulating PTHrP $(1-34)$ levels $(a)$ were significantly lower $(P<0.05)$ during lactation in BLG-Cre/PTHrPlox/- mice $(0.73 \pm 0.13 \mathrm{pM}, n=7)$ than in PTHrPlox/- controls $(1.18 \pm 0.19 \mathrm{pM}, n=3)$. Circulating calcium (b) and PTH (c) concentrations were not significantly different between PTHrPlox/- and BLG-Cre/PTHrPlox/- mice during lactation. Probably as a result of the reduced circulating PTHrP, urinary cAMP levels (d) and circulating 1,25-dihydroxy vitamin D concentrations (e) were also significantly reduced. Milk calcium (f) was not significantly different in BLG-Cre/PTHrPlox/- mice and controls. Bars represent the mean values of 3-12 samples. PTH concentrations were $3.8 \pm 1.5 \mathrm{pM}$ in PTHrPlox/- controls and $3.7 \pm 0.9 \mathrm{pM}$ in BLG-Cre/PTHrPlox/- mice. Although statistically insignificant, both plasma calcium and milk calcium are slightly lower in BLG-Cre/PTHrPlox/- mice $(8.8 \pm 0.2 \mathrm{mg} / \mathrm{dl}$ and $406.7 \pm 39.4 \mathrm{mg} / \mathrm{dl}, n=14)$ than in controls $(9.0 \pm 0.3 \mathrm{mg} / \mathrm{dl}$ and $471 \pm 78.5 \mathrm{mg} / \mathrm{dl}, n=9)$. Urinary cAMP was $33.9 \pm 0.6$ $\mu \mathrm{g} / \mathrm{mmol}$ creatinine in PTHrPlox/- controls $(n=7)$ and $19.3 \pm 0.8$ $\mu \mathrm{g} / \mathrm{mmol}$ creatinine in BLG-Cre/PTHrPlox/- mice $(n=11)$, while 1,25 dihydroxy vitamin D levels were $55.9 \pm 5.9 \mathrm{pg} / \mathrm{ml}$ in PTHrPlox/- mice $(n=3)$ and $43.5 \pm 2.2 \mathrm{pg} / \mathrm{ml}$ in BLG-Cre $/$ PTHrPlox/- mice $(n=6)$. 


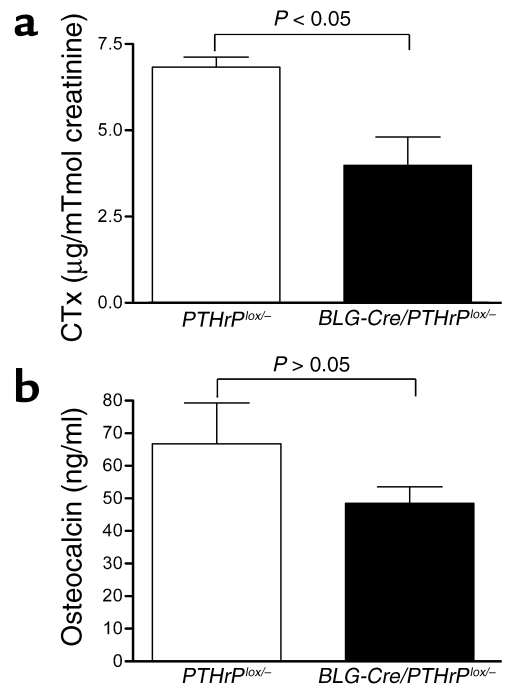

\section{Figure 4}

Biochemical markers of bone turnover were lower in lactating BLGCre/PTHrPlox/- mice. (a) Urine CTx levels were significantly lower $(P<0.05)$ in BLG-Cre $/ P T H r P l o x /-$ mice $(3.98 \pm 0.82 \mu \mathrm{g} / \mathrm{mmol}$ creatinine, $n=8)$ than in controls $(6.83 \pm 0.29 \mu \mathrm{g} / \mathrm{mmol}$ creatinine, $n=7)$. (b) Osteocalcin concentrations in plasma were lower in BLGCre/PTHrPlox/- mice than controls $(48.4 \pm 5.1 \mathrm{ng} / \mathrm{ml}, n=14$, and $66.8 \pm 12.5 \mathrm{ng} / \mathrm{ml}, n=9$, respectively), but these values were not significantly different.

lower in BLG-Cre/PTHrPlox/- mice (Table 1). Plasma osteocalcin (Figure $4 \mathrm{~b}$ ) levels tended to be lower in BLGCre $/$ PTHrPlox/- mice $(48.4 \pm 5.1 \mathrm{ng} / \mathrm{ml})$ than in PTHrPlox/mice $(66.8 \pm 12.5 \mathrm{ng} / \mathrm{ml})$, but they were not significantly different $(P=0.13)$. The number of osteoblasts/BPm $(\mathrm{ObN} / \mathrm{BPm})$ and the osteoblast suface/BS (ObS/BS), as determined by histomorphometry (Table 1 ), were also not different. The bone formation rate/tissue volume (BFR/TV) as measured by double-calcein labeling was significantly lower in BLG-Cre/PTHrPlox/- mice as compared with controls (Table 1), however. These data demonstrate that the removal of PTHrP from the mammary gland lowers maternal bone turnover during lactation.

Bone mass is preserved in lactating BLG-Cre/PTHrPlox/mice. The reduced rate of bone turnover in the $B L G$ $\mathrm{Cre} / \mathrm{PTHr} \mathrm{Plox}^{\mathrm{C}-}$ mice during lactation resulted in the preservation of bone mass. The PQCT measurements of tibias on day 12 of lactation (Table 2) showed that BLG-Cre/PTHrPlox/- mice $\left(327.2 \pm 9.5 \mathrm{mg} / \mathrm{cm}^{3}\right)$ had nearly $20 \%$ more bone mass (total density, $P<0.01$ ) than controls $\left(273.9 \pm 16.1 \mathrm{mg} / \mathrm{cm}^{3}\right)$. Furthermore, these values correlated with plasma PTHrP levels $\left(P<0.05, r^{2}=0.50\right)$. Parameters of bone volume as measured by histomorphometry (bone volume/TV $[\mathrm{BV} / \mathrm{TV}]$, trabecular number $[\mathrm{TbN}]$, trabecular separation [TbSp]), tended to be larger in BLG-Cre/PTHrPlox/mice, but there were no statistically significant differences. By PQCT, however, the areas and densities of both the cortical and trabecular compartments were significantly higher in $B L G$-Cre/PTHrPlox/- mice than in controls $(P<0.05)$. Similar results were obtained from serial measurements of bone density by DEXA (Figure 5). Importantly, bone mass was similar in $B L G$ $\mathrm{Cre} / \mathrm{PTHr} \mathrm{Plox}^{\mathrm{lo}}$ mice and controls at the beginning of lactation. Over the course of 1 week, however, PTHrPlox/- mice lost $16.8 \% \pm 1.5 \%$ (0.0092 \pm 0.00089 $\mathrm{g} / \mathrm{cm}^{2}$ ) of their bone mineral density (BMD), whereas BLG-Cre/PTHrPlox/- mice lost only 9.8\% $\pm 1.6 \%$ $\left(0.0051 \pm 0.00082 \mathrm{~g} / \mathrm{cm}^{2} ; P<0.01\right)$.

\section{Discussion}

A large amount of calcium is transferred from mother to offspring through milk, the supply of which represents a significant challenge to maternal calcium homeostasis. Part of the maternal adaptation to this stress is a rapid acceleration of bone resorption and bone loss. It has been shown that nursing women lose 6-8\% of vertebral bone mass during the first 6 postpartum months and lactating rodents can lose up to $35 \%$ of their bone mass over the course of 2-3 weeks (21). Given the rapidity and magnitude of lactational bone loss, there has been great interest in its regulation. A series of studies have suggested that circulating PTHrP might trigger increased bone resorption during lactation. First, circulating PTHrP levels have been shown to be elevated during lactation $(23,26-28,30$, 40). Second, suckling has been shown to increase mammary production of PTHrP and to increase nephrogenous cAMP production and urinary phosphate levels in lactating rats (24). Third, concurrent with increases in systemic PTHrP levels, hypoparathyroid patients have been shown to require reductions in doses of calcium and vitamin D during lactation $(41,42)$. Finally, Sowers et al. (23) reported a negative correlation between bone mass and PTHrP levels in lactating women. Our studies offer direct confirmation that

Table 1

Ex vivo PQCT analysis of tibias from day 12 lactating BLG-Cre/PTHrPlox/- mice and PTHrPlox/- littermate controls

\begin{tabular}{lccccccccc}
\hline & $\begin{array}{c}\text { OcS/BS } \\
(\%)\end{array}$ & $\begin{array}{c}\text { NOc/BPm } \\
(\text { no./mm) }\end{array}$ & $\begin{array}{c}\text { ObS/BS } \\
(\%)\end{array}$ & $\begin{array}{c}\text { NOb/BPm } \\
(\text { no./mm })\end{array}$ & $\begin{array}{c}\text { BFR/TV } \\
(\% / y r)\end{array}$ & $\begin{array}{c}\text { BV/TV } \\
(\%)\end{array}$ & $\begin{array}{c}\text { TbTh } \\
(\mu \mathrm{m})\end{array}$ & $\begin{array}{c}\text { TbSp } \\
(\mu \mathrm{m})\end{array}$ & $\begin{array}{c}\text { TbN } \\
(\mathrm{no} . / \mathrm{mm})\end{array}$ \\
PTHrPlox/- & $7.0 \pm 1.0$ & $2.3 \pm 0.3$ & $18.2 \pm 2.3$ & $21.8 \pm 3.4$ & $372.7 \pm 36.2$ & $6.1 \pm 0.5$ & $25.3 \pm 2.1$ & $402.2 \pm 48.4$ & $2.46 \pm 0.27$ \\
BLG-Cre/PTHrPlox/- & $3.0 \pm 0.5^{\mathrm{A}}$ & $1.0 \pm 0.1^{\mathrm{A}}$ & $18.7 \pm 1.9$ & $26.0 \pm 3.0$ & $219.5 \pm 30.0^{\mathrm{B}}$ & $6.8 \pm 1.2$ & $21.9 \pm 2.1$ & $379.9 \pm 96.1$ & $3.28 \pm 0.62$
\end{tabular}

Static and dynamic histomorphometric analysis of tibias from day 12 lactating BLG-Cre/PTHrPlox/- mice $(n=7$, static; $n=4$, dynamic) and $P$ THrPlox/- littermate controls $(n=4$, static and dynamic). Values are shown as mean \pm standard error. OcS/BS $(P<0.005), \mathrm{NOb} / \mathrm{BPm}(P<0.005)$, and BFR/TV $(P<0.05)$ were significantly lower in the BLG-Cre/PTHrPlox/- mice than in controls. OcS/BS, osteoblast surface as a percentage of bone surface; NOb/BPm, number of osteoblasts per mm bone perimeter; BFR/TV, bone formation rates as a function of tissue volume; BV/TV, trabecular bone volume as a function of tissue volume; TbTh, trabecular thickness; TbSp, Trabecular separation; Tbn, trabecular number. 
Table 2

Ex vivo PQCT analysis of tibias from day 12 lactating BLG-Cre/PTHrPlox/- mice and PTHrPlox/- littermate controls

\begin{tabular}{|c|c|c|c|c|c|}
\hline & $\begin{array}{l}\text { Total density } \\
\left(\mathrm{mg} / \mathrm{cm}^{3}\right)\end{array}$ & $\begin{array}{l}\text { Cortical density } \\
\qquad\left(\mathrm{mg} / \mathrm{cm}^{3}\right)\end{array}$ & $\begin{array}{l}\text { Trabecular density } \\
\qquad\left(\mathrm{mg} / \mathrm{cm}^{3}\right)\end{array}$ & $\begin{array}{l}\text { Cortical area } \\
\quad\left(\mathrm{mm}^{2}\right)\end{array}$ & $\begin{array}{c}\text { Trabecular area } \\
\left(\mathrm{mm}^{2}\right)\end{array}$ \\
\hline PTHrPlox/- & $273.9 \pm 16.1$ & $258.0 \pm 6.3$ & $175.1 \pm 14.0$ & $1.41 \pm 0.03$ & $1.48 \pm 0.10$ \\
\hline BLG-Cre/PTHrPlox/- & $327.2 \pm 9.5^{A}$ & $288.8 \pm 9.8^{B}$ & $208.4 \pm 8.1^{\mathrm{B}}$ & $1.54 \pm 0.04^{\mathrm{B}}$ & $1.90 \pm 0.14^{\mathrm{B}}$ \\
\hline
\end{tabular}

BLG-Cre/PTHrPlox/- mice $(n=14)$; PTHrPlox/- littermate controls $(n=9)$.Values are shown as mean \pm SE. Total, cortical, and trabecular density $(P<0.01$, $P<0.05, P<0.05$, respectively). ${ }^{A} P<0.01 ;{ }^{B} P<0.05$.

PTHrP functions as a systemic hormone and that it is likely an important regulator of bone turnover during lactation. When PTHrP is removed from the lactating mammary gland, circulating PTHrP levels are decreased, bone resorption rates are reduced, and bone mass is preserved.

BLG-driven expression of Cre was remarkably efficient in disrupting the PTHrP gene in MECs since PTHrP RNA was undetectable in the mammary glands of BLG-Cre/PTHrPlox/- mice, and PTHrP protein was undetectable in 12 out of 14 milk samples from these mice and was very low in the remaining two. Despite its importance to mammary development at other stages, removal of PTHrP had no deleterious effects on the structure of the lactating gland. Consistent with this finding, we did not observe any change in the level of RANK, RANKL, or OPG RNA expression in the mammary gland of $B L G-C r e / P T H r P l o x /-$ mice (data not shown), despite the fact that Fata et al. (43) demonstrated an effect of systemic PTHrP administration on mammary RANKL expression in nulliparous, ovariectomized mice.

The reduction in plasma PTHrP levels in the $B L G$ $\mathrm{Cre} / \mathrm{PTHr} \mathrm{Plox}^{l-}$ mice as compared with controls is direct evidence that PTHrP is secreted from the mammary gland into the circulation during lactation. BLG$\mathrm{Cre} / \mathrm{PTHrPlox/}$ mice also had reductions in urinary cAMP concentrations, which correlated with plasma PTHrP concentrations, and lower circulating 1,25dihydroxyvitamin D levels, suggesting reduced activation of the PTH1R in the kidney. Since PTH levels did not differ between $B L G$-Cre/PTHrPlox/- and control animals, these changes may be a reflection of the biological activity of the PTHrP secreted by the mammary gland. Therefore, the lactating mammary gland not only secretes copious amounts of PTHrP into milk, but also releases PTHrP into the bloodstream. The precise mechanism of this systemic release remains unknown. Simple paracellular leakage of PTHrP from the milk into the circulation is unlikely in light of the tight junctions that are necessary to maintain the large milkblood concentration gradients of multiple milk constituents. How mammary epithelial cells target different amounts of PTHrP for secretion at apical versus basolateral surfaces promises to be an interesting question for future research.

The removal of PTHrP from the mammary glands of lactating BLG-Cre/PTHrPlox/- mice resulted in a reduction in rates of bone resorption, as indicated by biochemical markers and measured by histomorphometry. As a result, at postpartum day 12 , the bone density of the BLG-Cre/PTHrPlox/- mice was significantly higher than that of littermate controls, as seen by ex vivo PQCT. In addition, serial BMD measurements by DEXA demonstrated that rates of bone loss were lower in BLG-Cre/PTHrPlox/- mice as compared with controls, resulting in a divergence of BMD between the two lines of mice over time. These data strongly suggest that the PTHrP secreted into the circulation during lactation promotes osteoclastic bone resorption and the loss of bone mineral.

Milk production as assessed by the growth rate of the pups appeared normal in the BLG-Cre/PTHrPlox/mice. Although several studies have suggested that PTHrP may be involved in calcium transport into milk $(12-15,44,45)$, the mean milk calcium level was only slightly and nonsignificantly lower in $B L G$ Cre/PTHrPlox/- mice than in littermate PTHrPlox/- controls. These data are inconsistent with a dominant role for PTHrP in regulating calcium transport into milk. Although pup growth was not affected by the lack of PTHrP in the milk of BLG-Cre/PTHrPlox/dams, this experimental system will be useful to examine other potential effects of milk PTHrP on neonates. A more thorough analysis of pups suckling dams producing PTHrP-deficient or PTHrP-replete milk is currently underway.

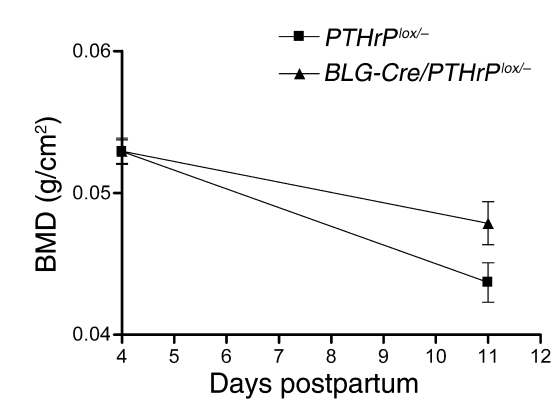

Figure 5

Bone density was measured in vivo at days 4 and 11 of lactation by DEXA. At day 4, the vertebral BMD of BLG-Cre/PTHrPlox/- mice $(n=6)$ and controls $(n=5)$ was $0.05294 \pm 0.002043 \mathrm{~g} / \mathrm{cm}^{2}$ and $0.05290 \pm 0.002030 \mathrm{~g} / \mathrm{cm}^{2}$. By day 11 of lactation, the BMD of the control mice had fallen to $0.04368 \pm 0.001386 \mathrm{~g} / \mathrm{cm}^{2}$, whereas the BMD of the BLG-Cre/PTHrPlox/- mice was $0.04786 \pm 0.001512$ $\mathrm{g} / \mathrm{cm}^{2}$. Therefore, the BLG-Cre/PTHrPlox/- mice lost significantly less bone mass during a 7-day time period during lactation than did controls $(P<0.01)$. 
Plasma calcium levels were not significantly lower in BLG-Cre/PTHrPlox/- mice compared with controls. This stability of the plasma calcium levels seems remarkable given that the transfer of calcium into milk did not decrease significantly, that PTH levels were not different, and that circulating PTHrP and 1,25-dihydroxy vitamin D levels and bone turnover were all reduced. Thus, despite a steady drain of calcium into milk and a decreased supply of calcium liberated from skeletal stores, $B L G$-Cre/PTHrPlox/- mice did not become hypocalcemic. At this point, the nature of this compensation remains unclear. We suggest two possible factors, however, that might contribute to the maintenance of systemic calcium levels. First, the BLG-Cre/PTHrPlox/- mice continued to lose bone, albeit at a reduced rate. Thus, removal of PTHrP did not completely inhibit the liberation of skeletal calcium stores. Second, it is likely that, in mice, dietary calcium serves as a more important source of the total calcium used for milk production than does skeletal calcium. Studies in our laboratory and by others have demonstrated that while lactating mice develop severe hypocalcemia in response to dietary calcium restriction, treatment with antiresorptive agents has little effect on systemic calcium levels (J. VanHouten, unpublished observations) (46). Although 1,25-dihydroxy vitamin $\mathrm{D}$ was reduced in the $B L G$-Cre/PTHrPlox/- mice, we did not limit dietary calcium. Thus, it is possible that some increase in calcium intake might have compensated for the decrease in skeletal calcium liberation. Future studies examining graded restrictions in dietary calcium in the BLG-Cre/PTHrPlox/- mice should help clarify the relative contributions of PTHrP-mediated bone loss and dietary calcium absorption to calcium fluxes during lactation.

In conclusion, we have deleted PTHrP from the mammary gland during lactation. In the absence of mammary gland-derived PTHrP, plasma PTHrP levels are lower, bone turnover is lower, and bone mass is preserved. These results suggest that the mammary gland actively participates in the regulation of maternal bone loss during lactation by releasing PTHrP into the circulation to act as an endocrine mediator of bone resorption.

\section{Acknowledgments}

This work was facilitated by the Yale Core Center for Musculoskeletal Disorders (NIH AR-46032) and supported by NIH grants DK-059719, DK-48108, CA94175, and DK-55501, and grant 008558 from the National Cancer Institute of Canada. We are grateful for the technical assistance of MaryAnn Mitnik, Tracy Nelson, Sherril Nieman, Nancy Troiano, and Kimberly Wilson. We thank Arthur Broadus for his helpful comments and critical review of this manuscript.

1. Wysolmerski, J.J., and Broadus, A.E. 1994. Hypercalcemia of malignancy: the central role of parathyroid hormone-related protein. Annu. Rev. Med. 45:189-200.
2. Philbrick, W.M., et al. 1996. Defining the roles of parathyroid hormone-related protein in normal physiology. Physiol. Rev. 76:127-173.

3. Wysolmerski, J.J., and Stewart, A.F. 1998. The physiology of parathyroid hormone-related protein: an emerging role as a developmental factor. Annu. Rev. Physiol. 60:431-460.

4. Strewler, G.J. 2000. The physiology of parathyroid hormone-related protein. N. Engl. J. Med. 342:177-185.

5. Thiede, M.A., and Rodan, G.A. 1988. Expression of a calcium-mobilizing parathyroid hormone-like peptide in lactating mammary tissue. Science. 242:278-280.

6. Ratcliffe, W.A., et al. 1990. Identification and partial characterization of parathyroid hormone-related protein in human and bovine milk. J. Endocrinol. 127:167-176.

7. Budayr, A.A., et al. 1989. High levels of a parathyroid hormone-like protein in milk. Proc. Natl. Acad. Sci. U. S. A. 86:7183-7185.

8. Wysolmerski, J.J., et al. 2001. Absence of functional type 1 parathyroid hormone $(\mathrm{PTH}) / \mathrm{PTH}$-related protein receptors in humans is associated with abnormal breast development and tooth impaction. J. Clin. Endocrinol. Metab. 86:1788-1794.

9. Wysolmerski, J.J., et al. 1998. Rescue of the parathyroid hormonerelated protein knockout mouse demonstrates that parathyroid hormone-related protein is essential for mammary gland development. Development. 125:1285-1294.

10. Wysolmerski, J.J., McCaughern-Carucci, J.F., Daifotis, A.G., Broadus, A.E., and Philbrick, W.M. 1995. Overexpression of parathyroid hormone-related protein or parathyroid hormone in transgenic mice impairs branching morphogenesis during mammary gland development. Development. 121:3539-3547.

11. Dunbar, M.E., et al. 2001. Temporally regulated overexpression of parathyroid hormone-related protein in the mammary gland reveals distinct fetal and pubertal phenotypes. J. Endocrinol. 171:403-416.

12. Care, A.D., Abbas, S.K., Ousey, J., and Johnson, L. 1997. The relationship between the concentration of ionised calcium and parathyroid hormone-related protein (PTHrP[1-34]) in the milk of mares. Equine Vet. J. 29:186-189.

13. Barlet, J.P., Champredon, C., Coxam, V., Davicco, M.J., and Tressol, J.C. 1992. Parathyroid hormone-related peptide might stimulate calcium secretion into the milk of goats. J. Endocrinol. 132:353-359.

14. Law, F.M., et al. 1991. Parathyroid hormone-related protein in milk and its correlation with bovine milk calcium. J. Endocrinol. 128:21-26.

15. Uemura, H., Yasui, T., Yoneda, N., Irahara, M., and Aono, T. 1997. Measurement of $\mathrm{N}$ - and $\mathrm{C}$-terminal-region fragments of parathyroid hormone-related peptide in milk from lactating women and investigation of the relationship of their concentrations to calcium in milk. J. Endocrinol. 153:445-451.

16. Prosser, C.G., Farr, V.C., and Davis, S.R. 1994. Increased mammary blood flow in the lactating goat induced by parathyroid hormonerelated protein. Exp. Physiol. 79:565-570.

17. Rong, H., et al. 1997. Parathyroid hormone-related protein in neonatal and reproductive goats determined by a sensitive time-resolved immunofluorometric assay. Eur. J. Endocrinol. 136:546-551.

18. Kukreja, S.C., et al. 1991. Lack of effects of neutralization of parathyroid hormone-related protein on calcium homeostasis in neonatal mice. J. Bone Miner. Res. 6:1197-1201.

19. Hillman, L.S., et al. 1994. Effect of parathyroid hormone-related peptide supplementation of soy protein formulas in the neonatal pig model. J. Bone Miner. Res. 9:1047-1052.

20. Prentice, A. 2000. Calcium in pregnancy and lactation. Annu. Rev. Nutr. 20:249-272.

21. Kovacs, C.S., and Kronenberg, H.M. 1997. Maternal-fetal calcium and bone metabolism during pregnancy, puerperium, and lactation. Endocr. Rev. 18:832-872.

22. Sowers, M., et al. 1998. Role of calciotrophic hormones in calcium mobilization of lactation. Am. J. Clin. Nutr. 67:284-291.

23. Sowers, M.F., et al. 1996. Elevated parathyroid hormone-related peptide associated with lactation and bone density loss. JAMA. 276:549-554.

24. Yamamoto, M., et al. 1991. Suckling-mediated increases in urinary phosphate and $3^{\prime}, 5^{\prime}$-cyclic adenosine monophosphate excretion in lactating rats: possible systemic effects of parathyroid hormone-related protein. Endocrinology. 129:2614-2622.

25. Ratcliffe, W.A., Thompson, G.E., Care, A.D., and Peaker, M. 1992. Production of parathyroid hormone-related protein by the mammary gland of the goat. J. Endocrinol. 133:87-93.

26. Lippuner, K., Zehnder, H.J., Casez, J.P., Takkinen, R., and Jaeger, P. 1996. PTH-related protein is released into the mother's bloodstream during location: evidence for beneficial effects on maternal calciumphosphate metabolism. J. Bone Miner. Res. 11:1394-1399.

27. Grill, V., et al. 1992. Parathyroid hormone-related protein: a possible endocrine function in lactation. Clin. Endocrinol. (Oxf.). 37:405-410.

28. Bucht, E., et al. 1995. Midmolecular parathyroid hormone-related peptide in serum during pregnancy, lactation and in umbilical cord 
blood. Eur. J. Endocrinol. 132:438-443.

29. Caplan, R.H., Wickus, G.G., Sloane, K., and Silva, P.D. 1995. Serum parathyroid hormone-related protein levels during lactation. J. Reprod. Med. 40:216-218.

30. Dobnig, H., et al. 1995. Elevated parathyroid hormone-related peptide levels after human gestation: relationship to changes in bone and mineral metabolism. J. Clin. Endocrinol. Metab. 80:3699-3707.

31. Karaplis, A.C., et al. 1994. Lethal skeletal dysplasia from targeted disruption of the parathyroid hormone-related peptide gene. Genes Dev. 8:277-289.

32. Selbert, S., et al. 1998. Efficient BLG-Cre mediated gene deletion in the mammary gland. Transgenic Res. 7:387-396.

33. He, B., et al. 2001. Tissue-specific targeting of the pthrp gene: the generation of mice with floxed alleles. Endocrinology. 142:2070-2077.

34. Dunbar, M.E., et al. 1998. Stromal cells are critical targets in the regulation of mammary ductal morphogenesis by parathyroid hormonerelated protein. Dev. Biol. 203:75-89.

35. Plawner, L.L., Philbrick, W.M., Burtis, W.J., Broadus, A.E., and Stewart, A.F. 1995. Cell type-specific secretion of parathyroid hormone-related protein via the regulated versus the constitutive secretory pathway. J. Biol. Chem. 270:14078-14084.

36. Broadus, A.E. 1979. Nephrogenous cyclic AMP as a parathyroid function test. Nephron. 23:136-141.

37. Reinhardt, T.A., Horst, R.L., Orf, J.W., and Hollis, B.W. 1984. A microassay for 1,25-dihydroxyvitamin D not requiring high performance liquid chromatography: application to clinical studies. J. Clin.
Endocrinol. Metab. 58:91-98.

38. Gundberg, C.M., Clough, M.E., and Carpenter, T.O. 1992. Development and validation of a radioimmunoassay for mouse osteocalcin: paradoxical response in the Hyp mouse. Endocrinology. 130:1909-1915.

39. Wagner, K.U., et al. 1997. Cre-mediated gene deletion in the mammary gland. Nucleic Acids Res. 25:4323-4330.

40. Ratcliffe, W.A. 1992. Role of parathyroid hormone-related protein in lactation. Clin. Endocrinol. (Oxf.). 37:402-404.

41. Anai, T., Tomiyasu, T., Takai, N., and Miyakawa, I. 1999. Remission of idiopathic hypoparathyroidism during lactation: a case report. J. Obstet. Gynaecol. Res. 25:271-273.

42. Mather, K.J., Chik, C.L., and Corenblum, B. 1999. Maintenance of serum calcium by parathyroid hormone-related peptide during lactation in a hypoparathyroid patient. J. Clin. Endocrinol. Metab. 84:424-427.

43. Fata, J.E., et al. 2000. The osteoclast differentiation factor osteoprotegerin-ligand is essential for mammary gland development. Cell. 103:41-50.

44. Kocabagli, N., Riond, J.L., Kung, K., and Wanner, M. 1995. Parathyroid hormone-related protein and calcium concentrations in milk and blood of ewes. Domest. Anim. Endocrinol. 12:215-218.

45. Seki, K., et al. 1997. Parathyroid-hormone-related protein in human milk and its relation to milk calcium. Gynecol. Obstet. Invest. 44:102-106.

46. Garner, S.C., Anderson, J.J., Mar, M.H., and Parikh, I. 1991. Estrogens reduce bone loss in the ovariectomized, lactating rat model. Bone Miner. 15:19-31. 